ORIGINAL ARTICLE

\title{
Review of treatment of bronchiolitis related apnoea in two centres
}

\author{
A Al-balkhi, H Klonin, K Marinaki, D P Southall, D A Thomas, P Jones, M P Samuels
}

Arch Dis Child 2005;90:288-291. doi: 10.1136/adc.2003.039404

See end of article for authors' affiliations

....................

Correspondence to: DrM P Samuels, Academic Department of Paediatrics, University Hospital of North Staffordshire, Stoke on Trent ST4 6QG, UK ; samuels@doctors.org.uk

Accepted 9 March 2004

\begin{abstract}
Aims: To determine whether the use of negative pressure ventilation (NPV) was associated with a lower rate of endotracheal intubation in infants with recurrent apnoea secondary to acute bronchiolitis.

Methods: Retrospective review of two paediatric intensive care units (PICU) databases and case notes; one PICU offered NPV.

Results: Fifty two infants with bronchiolitis related apnoea were admitted to the two PICUs (31 to the NPV centre). There were no significant differences between infants in the two centres in age and weight on admission, gestational age at birth, birth weight, history of apnoea of prematurity or chronic lung disease, days ill before referral, respiratory syncytial virus status, oxygen requirement before support, and numbers retrieved from secondary care centres. Respiratory support was provided to all 31 infants in the NPV centre (23 NPV, 8 PPV), and 19/21 in the non-NPV centre (18 PPV, 1 CPAP); the NPV centre had lower rates of endotracheal intubation rates $(8 / 31 \vee 18 / 21)$, shorter durations of stay (median $2 v 7$ days), and less use of sedation $(16 / 31 \vee 18 / 21)$. In the two years after the NPV centre discontinued use of NPV, 14/ $17(82 \%)$ referred cases were intubated, with a median PICU stay of 7.5 days.

Conclusions: The use of NPV was associated with a reduced rate of endotracheal intubation, and shorter PICU stay. A prospective randomised controlled trial of the use of NPV in the treatment of bronchiolitis related apnoea is warranted.
\end{abstract}

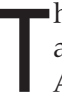
e incidence of apnoea in patients with bronchiolitis who are referred to hospital or intensive care is $10-25 \% .{ }^{1-3}$ Apnoea at admission and recurrent apnoea are significant risk factors for an infant needing endotracheal intubation and positive airway pressure ventilation (PPV); in turn, these are associated with increased morbidity. ${ }^{1-7}$

In one of our centres, negative pressure ventilation (NPV) has been developed and used for over six years in the treatment of respiratory failure arising from a number of different conditions, including bronchiolitis. ${ }^{8}$ The potential advantages of NPV include avoidance of the need for anaesthesia and intubation, and potential reductions in bronchoconstriction, bronchorrhoea, atelectasis, and secondary bacterial infection arising from the presence of an endotracheal tube and suction catheters in the lower respiratory tract.

As one method of assessment of NPV, we compared data between two paediatric intensive care units, one of which provided NPV as an additional means of respiratory support, to determine whether the use of NPV was associated with a reduced rate of endotracheal intubation in infants with recurrent apnoea secondary to acute bronchiolitis.

\section{SUBJECTS AND METHODS}

We reviewed the medical records and PICU charts of all patients with a diagnosis of bronchiolitis related apnoea admitted to two PICUs between March 1993 and November 1997. Patients were included in the analysis if they had been referred for intensive care primarily because of recurrent apnoea needing vigorous stimulation or bag-mask ventilation, or in association with inadequate respiratory effort, a presentation of bronchiolitis distinct from that involving respiratory distress. ${ }^{1-3}$ The diagnosis was established from the presentation of apnoea, and either confirmation from a nasopharyngeal aspirate (taken in all cases) of the presence of respiratory syncytial virus (RSV), or other features of bronchiolitis, including a coryzal prodrome, cough, wheeze and crackles, and hyperinflation on chest $x$ ray examination.

Each hospital had a six bedded PICU, run by consultant paediatricians with expertise in paediatric intensive care and staffed by paediatric doctors in training. Both units provided a retrieval service; patients were referred from secondary care centres to their usual PICU, and not because one centre had negative pressure ventilation.

Standard clinical care available in both centres included the use of methylxanthines (for example, caffeine), continuous positive airway pressure (CPAP) administered by nasal prongs or tube, and PPV. Further respiratory support was given for apnoea when infants had needed repeated bagmask ventilation and had either inadequate respiratory effort between apnoeic episodes, or severe respiratory acidosis. While CPAP was available in both centres, it was not routinely offered to infants with apnoea and tended to be used in spontaneously breathing infants with a rising oxygen requirement. One centre offered NPV, using purpose built equipment suitable for infants. ${ }^{8}$ This was provided after CPAP on some occasions, and where possible, before resorting to intubation and PPV. It was given as continuous negative extrathoracic pressure (CNEP, usually -4 to $-8 \mathrm{~cm} \mathrm{H}_{2} \mathrm{O}$ ), or if apnoea continued or respiratory distress increased, intermittent negative extrathoracic pressure (INEP, usual settings ranging from -20 to $-25 /-4$ to $-6 \mathrm{~cm} \mathrm{H}_{2} \mathrm{O}$, at rates of $10-20$ breaths per minute). Persistence of apnoea despite NPV lead to intubation and PPV. In the non-NPV centre, PPV was given at a point where NPV would have been offered in the NPV centre.

Abbreviations: CNEP, continuous negative extrathoracic pressure; CPAP, continuous positive airway pressure; INEP, intermittent negative extrathoracic pressure; NPV, negative pressure ventilation; PICU, paediatric intensive care unit; PPV, positive pressure ventilation; RSV, respiratory syncytial virus 
The data collected for each infant included age, weight, birth weight and gestation, history of prematurity, chronic lung disease or apnoea of prematurity, referral source, duration of illness and stay on PICU, and whether treated with sedation, antibiotics, methylxanthines, CPAP, NPV, or PPV. The data for infants within each PICU were compared, using non-parametric tests as appropriate (Mann-Whitney, $\chi^{2}$, and Fisher's exact test). In 1999, the NPV centre stopped using negative pressure ventilation because of unsubstantiated allegations about its safety, and a need to develop newer equipment. Data on the treatment of infants referred with bronchiolitis related apnoea to the NPV centre were collected for the 24 month period after the use of NPV was discontinued.

\section{RESULTS}

For the period that data were collected from both PICUs, 52 infants with bronchiolitis related apnoea were admitted (31 to the NPV centre). There were no significant differences between the admission characteristics of infants admitted to the two units (see table 1).

Some form of respiratory support (PPV, CPAP, or NPV) was given to all 31 infants in the NPV centre, and to 19/21 in the non-NPV centre. In the non-NPV centre, two infants received no respiratory support, one received theophylline and nasal CPAP for 30 hours, and $18(86 \%)$ patients received PPV. In the NPV centre, CPAP was tried in seven patients, but was poorly tolerated, two progressing to PPV and five to NPV. Assisted ventilation with either PPV or INEP was given to 24/ 31 (77\%) infants: INEP 16, PPV 8. Eight patients (26\%) underwent endotracheal intubation and received PPV in the NPV centre, significantly fewer than the $18(86 \%)$ in the non-NPV centre $(\mathrm{p}<0.001)$.

No infant had pneumonia or acute respiratory distress syndrome, but four in the NPV centre and eight in the nonNPV centre had atelectasis at some time on their chest radiographs. Of the eight patients who received PPV in the NPV centre, one had congenital heart disease and was transferred for extracorporeal membrane oxygenation, one received phenobarbitone for seizures, and six were intubated outside the PICU, by the referring or transfer teams. None of these patients was below 34 weeks gestation at birth or had a history of apnoea of prematurity. The patients ventilated in the non-NPV centre had no other complicating factors noted.

Sedation was used in $16(52 \%)$ patients in the NPV centre, eight of whom were intubated and ventilated, and in 18 $(86 \%)$ of the patients in the non-NPV centre $(\mathrm{p}<0.05)$. More antibiotics were used in the non-NPV centre $(p=0.036)$. Seventeen patients in the NPV centre had methylxanthines $(54 \%)$ compared to six $(28 \%)$ in the nonNPV centre $(p=0.06)$. Of those who received methylxanthines, 5/6 patients in the non-NPV centre required PPV compared to $2 / 17$ in the NPV centre.

The median PICU unit stay in the NPV centre was 2 days compared to 7 days in the non-NPV centre $(p<0.001)$. One patient of 5 weeks of age with pertussis and respiratory syncytial virus responded well to NPV and was transferred early to the high dependency area on the general ward.

During the 24 months after discontinuation of the use of NPV, the NPV centre received a further 17 referrals of infants with bronchiolitis related apnoea. Fourteen (82\%) were intubated and ventilated, and stayed on the PICU for a median of 7.5 days, data similar to those for the non-NPV centre.

\section{DISCUSSION}

When we compared treatment of infants admitted with bronchiolitis and a predominantly apnoeic component in two PICUs over a contemporaneous five year period, we found that the use of non-invasive ventilatory support was associated with a substantially lower rate of endotracheal intubation and PPV. Furthermore, the duration of stay on the PICU was significantly shorter in the NPV centre. This lends support to the hypothesis that the addition of NPV as a respiratory support for apnoea in bronchiolitis may lead to less short term morbidity.

\begin{tabular}{|c|c|c|c|c|}
\hline & NPV centre & Non-NPV centre & Statistical test & $\mathrm{p}$ value \\
\hline Number of patients & 31 & 21 & & \\
\hline Male (\%) & $20(64.5)$ & $14(67)$ & xs & 0.87 \\
\hline Gestational age at birth (weeks) & & & $\mathrm{mw}$ & 0.97 \\
\hline Median & 34 & 34 & & \\
\hline Range & $23-40$ & $27-40$ & & \\
\hline Birth weight (g) & & & $\mathrm{mw}$ & 0.7 \\
\hline $\begin{array}{l}\text { Median } \\
\text { Range }\end{array}$ & $\begin{array}{l}1960 \\
630-4309\end{array}$ & $\begin{array}{l}2260 \\
755-3620\end{array}$ & & \\
\hline History of apnoea of prematurity (\%) & $10(32)$ & $7(33)$ & xs & 0.933 \\
\hline $\begin{array}{l}\text { History of chronic lung disease of } \\
\text { prematurity }(\%)\end{array}$ & $6(19)$ & $2(9)$ & xs & 0.29 \\
\hline Transfers in (\%) & $20(65)$ & $13(62)$ & xs & 0.84 \\
\hline Transfer in ambulance with NPV & 13 & 0 & & \\
\hline Admission age (days) & & & $\mathrm{mw}$ & 0.97 \\
\hline Median & 34 & 38 & & \\
\hline Range & $5-243$ & $11-131$ & & \\
\hline Days ill & & & $\mathrm{mw}$ & 0.42 \\
\hline Median & 2 & 3 & & \\
\hline Range $^{*}$ & $1-21$ & $1-14$ & & \\
\hline Admissions weight (g) & & & $\mathrm{mw}$ & 0.8 \\
\hline Median & 3460 & 3500 & & \\
\hline Range & $1500-5270$ & $1800-5000$ & & \\
\hline RSV positive (\%) & $22(71)$ & $18(86)$ & xs & 0.18 \\
\hline Maximum oxygen (\%) before referral & & & $\mathrm{mw}$ & 0.374 \\
\hline Median & 70 & 90 & & \\
\hline Ranget & $21-100$ & $21-100$ & & \\
\hline
\end{tabular}




\begin{tabular}{|c|c|c|c|c|}
\hline & NPV centre & Non-NPV centre & Statistical test & $p$ value \\
\hline Number of patients & 31 & 21 & & \\
\hline CNEP alone & 7 & & & \\
\hline CPAP & $8^{*}$ & 1 & & \\
\hline INEP (acute phase) & & & & \\
\hline NPV during weaning from PPV & & & & \\
\hline PPV (\%) & $8(26)$ & $18(86)$ & xs & $<0.001$ \\
\hline Duration PPV (days) & & & $\mathrm{mw}$ & 0.005 \\
\hline Median & 3 & 5 & & \\
\hline Range & $1-7$ & $0-12$ & & \\
\hline \multicolumn{5}{|l|}{ Peak pressure IPPV $\left(\mathrm{cm} \mathrm{H}_{2} \mathrm{O}\right)$} \\
\hline Median & 21.5 & 30 & & \\
\hline Range & $18-28$ & $16-42$ & & \\
\hline Use of sedation (\%) & $\begin{array}{l}16 \text { (52) } \\
{[8 \text { had PPV] }}\end{array}$ & $18(86)$ & Fisher's exact & 0.011 \\
\hline \multirow{2}{*}{$\begin{array}{l}\text { Use of methylxanthines (\%) } \\
\text { Patients on methylxanthines ventilated } \\
\text { with PPV (\%) }\end{array}$} & $17(55)$ & $6(28)$ & xs & 0.061 \\
\hline & $2(12)$ & $5(83)$ & & \\
\hline $\begin{array}{l}\text { Patients on methylxanthines receiving } \\
\text { NPV (\%) }\end{array}$ & $15(88)$ & & & \\
\hline Use of antibiotics (\%) & $22(71)$ & $20(95)$ & xs & 0.036 \\
\hline Days in PICU & & & $\mathrm{mw}$ & 0.001 \\
\hline Median & 2 & 7 & & \\
\hline Range & $0-8+$ & $2-13$ & & \\
\hline
\end{tabular}

This study has limitations, specifically because it is a retrospective review of clinical practice in two PICUs, rather than a prospective randomised controlled trial. Firstly, it is difficult to be certain how well the populations compare. It could be argued that the infants referred to the non-NPV unit were more seriously ill and therefore more likely to need intubation and ventilation. This is supported by the fact that infants ventilated in the non-NPV centre received higher ventilatory pressures and a longer duration of ventilation. We cannot be certain that referral patterns and other indicators of illness, which have a bearing on the clinical course and prognosis, were similar. However, the admission characteristics of these two cohorts were similar, including days ill, and age and oxygen requirement at the time of PICU admission.

Secondly, retrospective data collection is likely to be more prone to missing or incorrectly recorded data. Nevertheless, the fact that these were both local and tertiary referrals over a long time period makes it likely that the two units were dealing with similar populations, and this is again supported by the similarities in the admission characteristics.

Thirdly, confounding factors in this retrospective analysis include the greater use of CPAP and methylxanthines in the NPV centre, which could have contributed to the lower rate of intubation. We have found little published evidence in support of the use of CPAP in the treatment of apnoea in bronchiolitis, ${ }^{9}$ and this is confirmed by the fact that $7 / 8$ patients who received CPAP tolerated it poorly and went on to receive additional respiratory support.

Since our study, it has been reported that methylxanthines may have a role in reducing apnoea in bronchiolitis, although this report involved a small study which did not examine intubation rates. ${ }^{10}$ All 17 infants treated with methylxanthines in the NPV centre and five of six infants in the non-NPV centre needed further respiratory support. Methylxanthines do not appear to have prevented the need for further support, thus making the increased use of CPAP and methylxanthines in one centre less likely to be the cause of the lower intubation rates.
There was a clear difference in the proportion of infants needing endotracheal intubation and PPV, and this might be attributed to the use of NPV. It is likely that the reduced rate of endotracheal intubation explains the lower rate of use of antibiotics and sedation, both usually being used when infants are intubated for lower respiratory infections. NPV could be used without a need for anaesthesia or sedation; this can reduce the potential for problems with withdrawal of sedation that can complicate PPV and prolong the duration of stay on the PICU.

Since NPV was removed as a treatment for bronchiolitis in one centre, the rate of intubation and duration of stay on the PICU has increased to that found in the non-NPV centre. Infants receiving the more prolonged and intensive treatment now currently provided may be at increased risk of complications. We would advocate for a randomised, prospective controlled trial of the use of negative pressure ventilation as a respiratory support in bronchiolitis related apnoea.

\section{ACKNOWLEDGEMENTS}

We would like to thank Miss Angie Sowerby for typing the manuscript.

\section{Authors' affiliations}

A Al-balkhi, H Klonin, D A Thomas, Department of Paediatrics, University Hospital, Queen's Medical Centre, Nottingham, UK K Marinaki, D P Southall, M P Samuels, Academic Department of Paediatrics, University Hospital of North Staffordshire, Stoke on Trent, Staffordshire, UK

P Jones, Department of Mathematics, Keele University, Staffordshire, UK Competing interests: none declared

\section{REFERENCES}

1 Njoku DB, Kliegman RM. Atypical extrapulmonary presentations of severe respiratory syncytial virus infection requiring intensive care. Clin Pediatr (Phila) 1993;32:455-60

2 Anas N, Boettrich C, Hall CB, et al. The association of apnea and respiratory syncytial virus infection in infants. J Pediatr 1982;101:65-8. 
3 Bruhn FW, Mokrohisky ST, McIntosh K. Apnea associated with respiratory syncytial virus infection in young infants. J Pediatr 1977;90:382-6.

4 Lebel MH, Gauthier M, Lacroix J, et al. Respiratory failure and mechanical ventilation in severe bronchiolitis. Arch Dis Child 1989;64:1431-7.

5 Kneyber MC, Brandenburg AH, de Groot R, et al. Risk factors for respiratory virus associated apnoea. Eur J Pediatr 1998;157:331-5.

6 Wang EEL, Law BJ, Stephens D. Pediatric Investigators Collaborative Network on Infections in Canada (PICNIC) prospective study of risk factors and outcomes in patients hospitalized with respiratory syncytial viral lower respiratory tract infection. J Pediatr 1995;126:212-19.
7 Gavin R, Anderson B, Percival T. Management of severe bronchiolitis: indications for ventilator support. N Z Med J 1996;109:137-9.

8 Samuels MP, Southall DP. Negative extrathoracic pressure in treatment of respiratory failure in infants and young children. $B M J$ 1989;299: 1253-7.

9 McNamara F, Sullivan CE. Nasal CPAP treatment in an infant with respiratory syncytial virus-associated apnea. Pediatr Pulmonol 1997;24:218-21.

10 Tobias JD. Caffeine in the treatment of apnea associated with respiratory syncytial virus infection in neonates and infants. South Med J 2000;93:294-6.

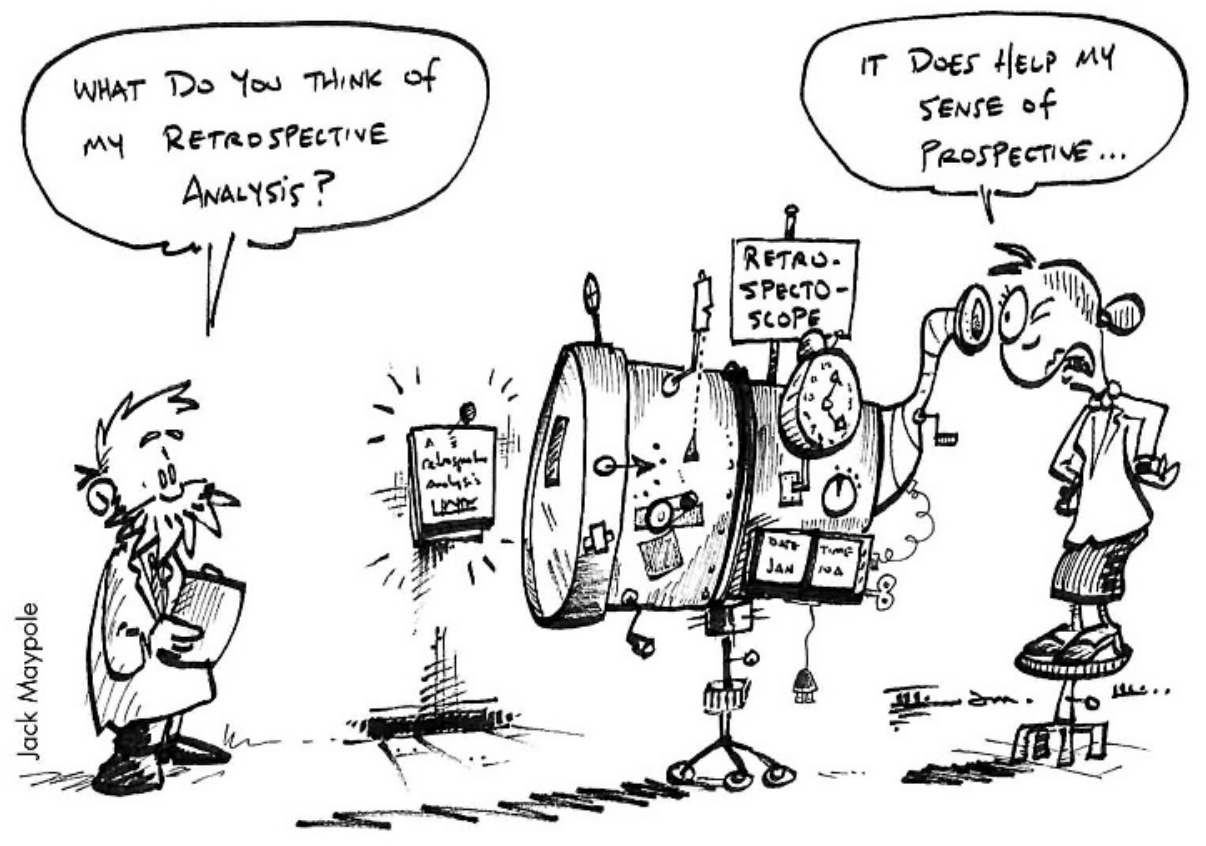

